\title{
Separation of Alteration Zones on ASTER Data and Integration with Drainage Geochemical Maps in Soltanieh, Northern Iran
}

\author{
Faranak Feizi", Edris Mansuri \\ Department of Mining Engineering, Faculty of Engineering, South Tehran Branch, Islamic Azad University, Tehran, Iran \\ Email: feizi.faranak@yahoo.com
}

Received February 3, 2013; revised March 8, 2013; accepted April 8, 2013

Copyright (C) 2013 Faranak Feizi, Edris Mansuri. This is an open access article distributed under the Creative Commons Attribution License, which permits unrestricted use, distribution, and reproduction in any medium, provided the original work is properly cited.

\begin{abstract}
The Soltanieh area is a part of Tarom volcano-plutonic zone that is located in north-west of Zanjan province in northwest of Iran. Advanced Space borne Thermal Emission and Reflection Radiometer (ASTER) image processing have been used for mapping hydrothermal alteration zones in studied area. To separate the alternation zones; False Color Composite (FCC), Least Square Fit (LS-Fit), Minimum Noise Fraction (MNF) and Spectral Angel Mapper (SAM) techniques have been applied on ASTER data and iron oxide, argillic, phyllic and propylitic zones have been separated. At last, the final alteration map is integrated with drainage geochemical maps of $\mathrm{Cu}, \mathrm{Zn}$ and $\mathrm{Pb}$ minerals for introducing the probable high potential zones.
\end{abstract}

Keywords: Alteration; Lineament; ASTER; Iran; Soltanieh

\section{Introduction}

The Advanced Space borne Thermal Emission and Reflection Radiometer (ASTER) is an advanced multispectral imager that has launched on board NASA's Terra spacecraft in December, 1999 [1]. ASTER covers a wide spectral region with 14 bands from the visible to the thermal infrared with high spatial, spectral and radiometric resolution. An additional backward-looking near-infrared band provides stereo coverage. The spatial resolution varies with wavelength: $15 \mathrm{~m}$ in the visible and near-infrared (VNIR), $30 \mathrm{~m}$ in the short wave infrared (SWIR), and $90 \mathrm{~m}$ in the thermal infrared (TIR) [2]. Develop methods for mapping rock types has been one of the main goals of geological remote sensing research. The altered rocks have received much attention because of their economic potential and favorable spectral characteristics for remote identification [3]. Hydrothermal alterations such as phyllic, argillic, potassic, and propylitic are associated with Porphyry-type deposits. Hydroxyl minerals are abundant in the phyllic, argillic and potassic zones. Also an oxide zone is developing over many of the porphyry bodies, which are rich in iron oxide minerals. These alteration minerals can detect by remote sensing techniques.

${ }^{*}$ Corresponding author.
[4,5]. In Iran, satellite data such as TM, ETM+, and ASTER SWIR bands have been used by geologists for exploration purposes.

For example Azizi et al. (2010) introduced hydrothermal alterations in east of Zanjan. this research is important because the presence of high value intermediate to acidic igneous rocks (late Cretaceous to Tertiary) and copper and gold mineralization in these host rocks in the northern parts of Iran (Figure 1). With using the exploration methods such as geological and drainage geochemical keys and combination them with satellite data In this area, the authors have identified the hopeful potential zones in Soltanieh.

\section{Geology Setting}

The study area is located between longitudes E48 $30^{\prime} 49^{\circ}$ and latitudes $\mathrm{N} 36^{\circ} 36^{\circ} 30^{\prime}$ in the southern part of Zanjan (Soltanieh 1:100,000 sheet) (Figure 2). The litho logy of this area is composed of Precambrian (Kahar and Bayandor formation) to Eocene pyroclastic rocks (Karaj formation). Pyroclastic rocks in the northern part of Iran, as in other areas of Alborz, are composed of green tuff with an interlayer of limestone and form a general curved arc pointing to the north. Pyroclastic rocks are often accompanied by lava flows: andesite, basaltic andesite, and 


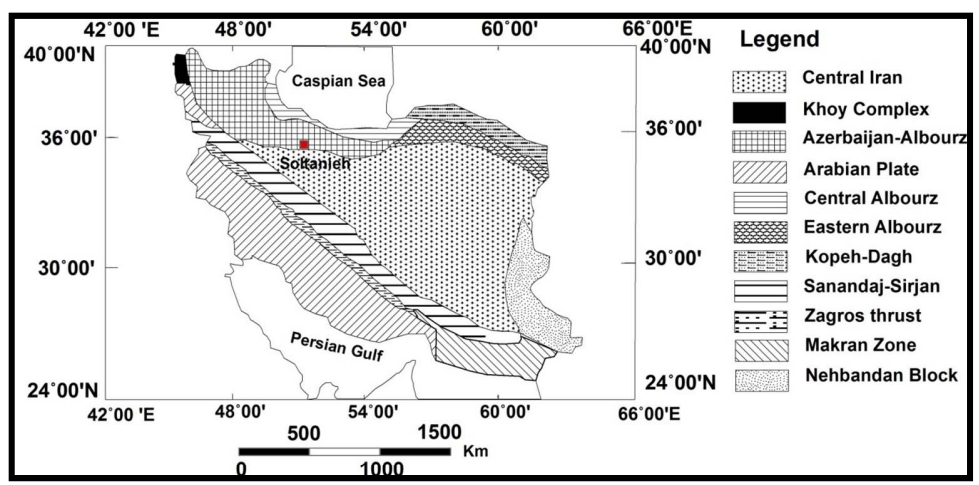

Figure 1.Tectonic map of Iran (Stocklin \& Nabavi, 1972).

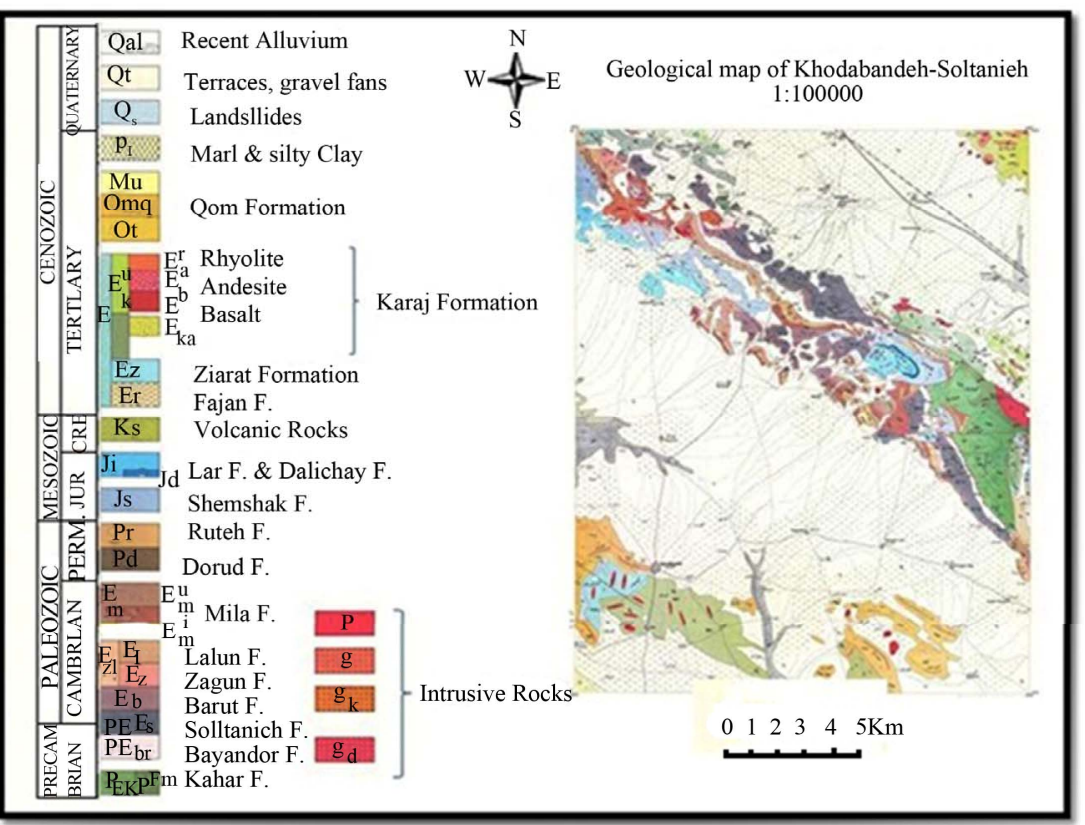

Figure 2. 1:100,000 Geological map of Soltanieh-Khodabandeh (Geological Survey of Iran, 1994).

porphyritic and non-porphyritic rhyodacite (Figure 2). One of the prominent features of magmatic highlands in this area is the existence of large granitic and granodioritic bodies, which have penetrated the Eocene pyroclastic rocks (Karaj formation). These represent post-Eocene intrusive bodies of the Pyrenean orogenic phase intruding in the direction of very deep fundamental faulted zones in the Tarom mountain ranges. Because this area is the southwest one quarter of 1:250,000 Zanjan geological map, we can follow the original trend of Tarom mountains in the other places too. The presence of $\mathrm{Cu}, \mathrm{Pb}$ and $\mathrm{Zn}$ mineralization in 3 other 1:100,000 geological maps which are adapted on the main trend and alteration halos in volcanic clastic rocks of Eocene origin are one of the characteristic consequences of these intrusive events. Mineralization of gold, copper, lead-zinc, and kaolinite is associated with these hydrothermal alteration halos [6]. There are about $13 \mathrm{Cu}$ indexes in eastern Tarom [7]. Va- rious types of mineral resources exist in this territory, which have made this province a high-potential mineral resource domain in Iran. In Tarom, magmatic-arc porphyry copper deposits and epithermal gold mineralization potentials have been observed (http://www.ngdir.ir). Although these mineralization and alterations are known in the other three 1:100,000 map of Zanjan sheet, but there are just one or two indexes of metallic mineralization in the studied area. This research is shown the potential of mineralization in this part, cause of continuing the alteration zones.

\section{Materials and Methods}

\section{ASTER Data}

The ASTER is an advanced optical sensor comprised of 14 spectral channels ranging from the visible to thermal infrared region. It will provide scientific and also practi- 
cal data regarding various field related to the study of the earth $[8,9]$. Various factors affect the signal measured at the sensor, such as drift of the sensor radiometric calibration, atmospheric and topographical effects. For accurate analysis, all of these corrections are necessary for remote sensing imagery [10]. To this end, at the beginning of the path, data set AST_L1B_003_2007978246 in hierarchical data format (HDF) was used for this research and radiance correlation such as wavelength, dark subtract and log residual by ENVI4.4 software which is essential for multispectral images, were implemented. In this study, False Color Composite, Least Square Fit, Minimum Noise Fraction and Spectral Angel Mapper methods were used on ASTER data for seperation of alteration zones.

\section{Data Preprocessing}

The ASTER sensor was launched in December 1999 on board the Earth Observation System (EOS) US Terra satellite to record solar radiation in 14 spectral bands (Table 1). ASTER measures reflected radiation in three bands between 0.52 and $0.86 \mathrm{~lm}$ (visible and near-infrared (VNIR) region) and in six bands from 1.6 to $2.43 \mathrm{~lm}$ (shortwave infrared (SWIR) region), with 15- and 30-m spatial resolution, respectively. Furthermore, the ASTER sensor also has a back-looking VNIR telescope with 15$\mathrm{m}$ resolution. Thus, stereoscopic VNIR images can be acquired at $15-\mathrm{m}$ resolution. In addition, emitted radiation is measured at $90-\mathrm{m}$ resolution in five bands from 8.125 to $11.65 \mathrm{~lm}$ (thermal infrared (TIR) region) [11]. The swath width is $60 \mathrm{~km}$, but ASTER's pointing capability extends the total cross-track viewing capability to 232 $\mathrm{km}$. A very important aspect of the EOS program is that the low cost of participation includes the open availability of the data from all the instruments, including ondemand standard products. ASTER standard products include VNIR and SWIR surface radiance, reflectance, and brightness, temperature at the sensor, TIR surface radiance and emissivity, surface kinetic temperature, décorrelation-stretch images, and digital-elevation models (DEM). The conclusions of the NASA Jet Propulsion Laboratory in 1995 showed that VNIR data are sensitive to the presence of iron oxide minerals; that the SWIR data high-light the presence and variability of minerals with hydroxyl radicals and carbonates, such as clays, alunite, and lime-stone; and that the TIR data are sensitive to differences in silica-bearing rocks, either in the presence of or in the absence of the other mineral constituents. Data set 200801_363 in hierarchical data format (HDF) was used for this research. To remove atmospheric and topographic effects from ASTER SWIR data, the log-residual method (LRM) [12] was used. The logresidual algorithm reduces noise from topography, instruments, and sun illumination, and was available as part of the analytical module used. The resulting data can be assumed to be more representative of the soils or lithologies of the exposed areas than the unprocessed data. Hence, a spectrum generated from data treated using the log-residual method will be more closely comparable to its corresponding library spectrum. Because the log-residual algorithm reduces noise from topography, instruments, and sun illumination, the processed ASTER SWIR data will allow comparison of the synthesized spectrum with those from the library. Applying log-residual processing to ASTER visible and near-infrared (VISNIR) bands is not recommended because there may be problems with additive atmospheric effects [3].

\section{Result and Discussion}

\section{Hydrothermal Alteration Detection}

Many image analysis and processing techniques can use to interpret the remote sensing spectral data. In this research, False Color Composite (FCC), Least Square Fit (LS-Fit), Minimum Noise Fraction (MNF) and Spectral Angel Mapper (SAM) methods were used on ASTER data for discrimination of alteration zones.

\subsubsection{False Color Composite (FCC)}

The studies on resampling of USGS standard (Figure 3) curves on ASTER bands show that Al-OH minerals such as Kaolinite, muscovite, montmorilonite and illite, (major minerals for phyllic and argillic alteration zones) have the most reflection in B4 on SWIR. Also, Mg-OH minerals such as chlorite and epidote that are remarkable for

Table 1. Wavelength ranges and spatial resolutions of ASTER bands (Abrams, 2000).

\begin{tabular}{|c|c|c|c|}
\hline Module & VNIR & SWIR & TIR \\
\hline Spectral bandwidth $(\mu \mathrm{m})$ & $\begin{array}{c}\text { Band 1 } 0.52-0.60 \\
\text { Band 2 } 0.63-0.69 \\
\text { Band 3 N } 0.78-0.86 \\
\text { Band 3 B } 0.78-0.86 \text { (backward looking) }\end{array}$ & $\begin{array}{l}\text { Band } 41.650-1.700 \\
\text { Band } 52.145-2.185 \\
\text { Band } 62.185-2.225 \\
\text { Band } 72.235-2.285 \\
\text { Band } 82.295-2.395 \\
\text { Band } 92.360-2.430\end{array}$ & $\begin{array}{l}\text { Band } 108.125-8.475 \\
\text { Band } 118.475-8.825 \\
\text { Band } 128.925-9.275 \\
\text { Band } 1310.25-10.95 \\
\text { Band } 1410.95-11.65\end{array}$ \\
\hline Spatial resolution (m) & 15 & 30 & 90 \\
\hline
\end{tabular}


propylitic alteration zones have the most reflection in Bands 4 and 5 on SWIR [13].

Therfore, phyllic and argillic alteration zones were shown reddish to pink and propylitic alteration zone was shown green in 468 False Color Composite (FCC) on SWIR [14] (Figure 4).
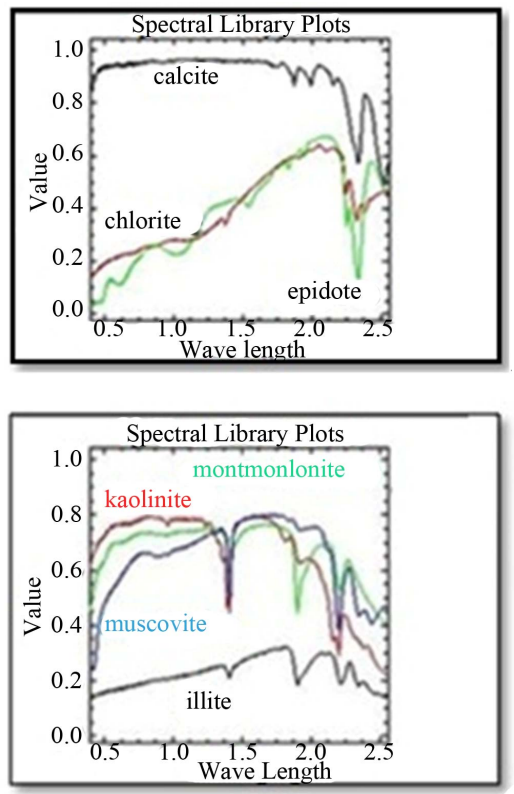

Figure 3. The remarkable mineral reflection for propylitic, phyllic and argillic zones.

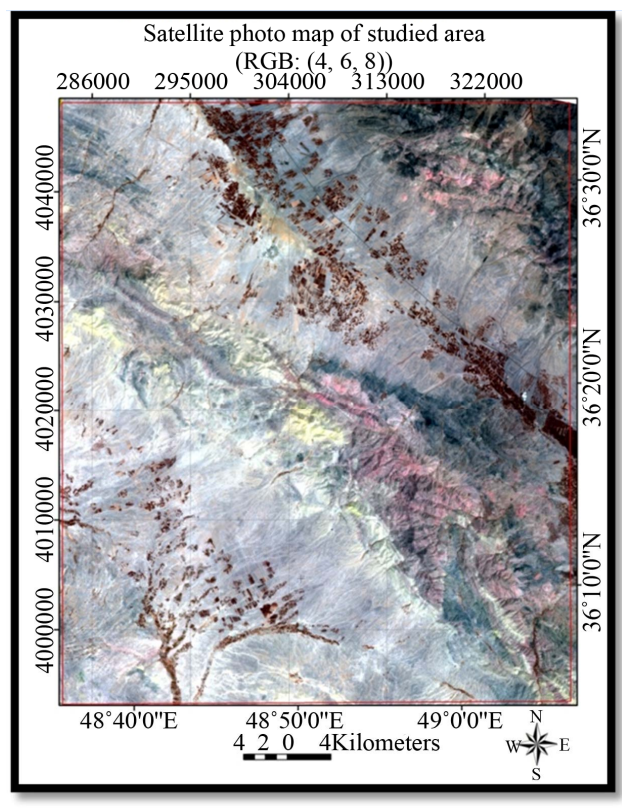

Figure 4. False-color composite in $R G B$ mode $(R=4, G=6$, $B=8)$. In this color composite, propylitic alteration appears as green, and phyllic alteration zones with large quantities of Al-OH minerals are pinkish to yellowish in color (For interpretation of the references to color in this figure legend, the reader is referred to the web version of this article).

\subsubsection{Least Squares Fitting (LS-Fit)}

The technique assumes that the bands used as input values are behaving as the variables of a linear expression and the " $y$ " value of the equation, namely the predicted band information, gives us a calculated output value. This predicted band is what that band should be according to the linear equation. The minerals which are sensitive to a specific band are then differentiated from the features which are reflective to the other bands as well; just by taking the difference between the predicted values and the original values [15]. Distribution of iron oxide was created by using all the 3 visible and near-infrared (VNIR) bands as the input bands and VNIR-b1 as the modeled band Also, argillic, phyllic and propylitic alterations were mapped by using residual band SWIR-b4, residual band SWIR-b6 and residual SWIR-b9 (Figure 5).

\subsubsection{Minimum Noise Fraction (MNF)}

The Minimum Noise Fraction (MNF) transformation is used to determine the inherent dimensionality of image data, segregate noise in the data, and reduce the computational requirements for subsequent processing (Figure 6) [16]. MNF involves two steps; in first step which is also called noise whitening, principal components for noise covariance matrix are calculated. This step decorrelates and rescales the noise in the data. In second step principal components are derived from the noise whitened data. The data can then be divided into two parts. One part associated with large Eigen values and the other part with near unity Eigen values and noise dominated images. Using data with large Eigen values separates the noise from the data, and improves spectral results [17]. MNF analysis can identify the locations of spectral signature anomalies. This process is of interest to exploration geologist because spectral anomalies are often indicative of alterations due to hydrothermal mineralization [18]. MNF Bands 3, 6, 4 and 7 were used for iron oxide, argillic, phyllic, propylitic and silica alterations.

\subsubsection{Spectral Angle Mapper (SAM)}

The Spectral Angle Mapper (SAM) is a classification technique that permits rapid mapping by calculating the spectral similarity between the image spectrums to reference reflectance spectra. SAM measures the spectral similarity by calculating the angle between the two spectra, treating them as vectors in n-dimensional space $[18$, 19]. The image spectra were compared with USGS Digital Spectral Library (Minerals) [20]. Figure 7 shows selected minerals spectral library plots that related to iron oxide and propylitic alterations. Chlorite and epidot representative of propylitic zone were selected in Figures 4 and 8 mineral spectral representative of iron oxide include jarosite, hematite, goethite and limonite were shown 

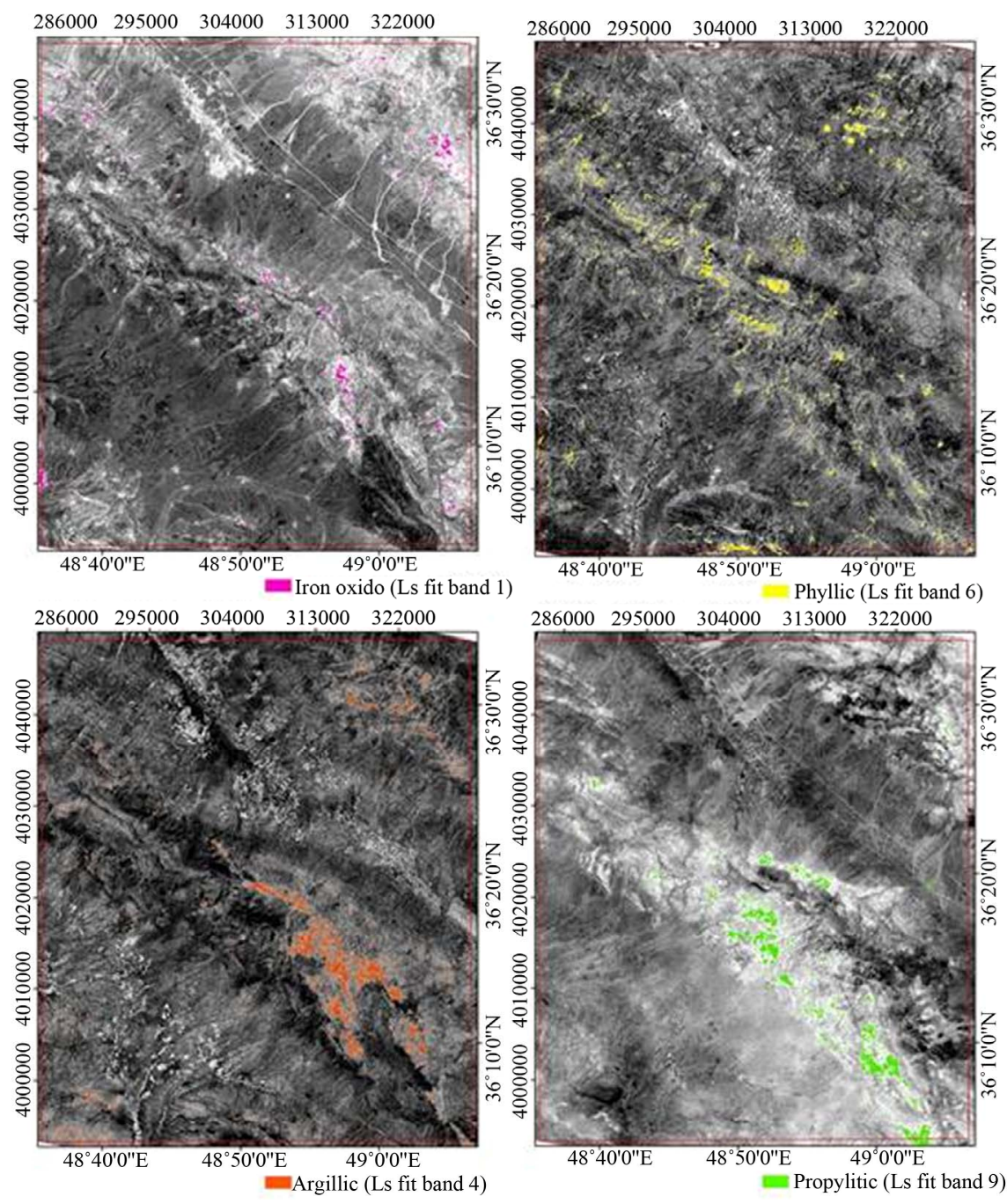

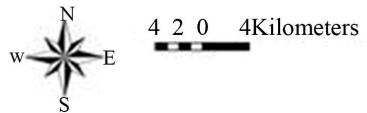

Figure 5. The iron oxide, argillic, phyllic and propylitic images prepared based on LS-Fit method.

\section{in Figure 9.}

At last with Integration of the argillic, phyllic, propylitic and iron oxide maps, the Final alteration map of studied area was prepared (Figure 10).

\section{Integration of Alteration and Drainage Geochemical Prospecting}

In this part, the outhors used statistic methods. So if data didn't follow the normal function, the mean value will be threshold that includes 2 parts: the background and anomaly. the elements histogram diagrams show that $\mathrm{Cu}, \mathrm{Pb}$ and $\mathrm{Zn}$ have abnormal dispersion. So threshold will be equal to mean. Then the anomaly points could separate from the background in three different maps which are shown in red point for $\mathrm{Zn}$, green point for $\mathrm{Pb}$ and blue for $\mathrm{Cu}$ with using Surfer 10 software. After that, these 3 maps were integrated as one drainage geochemical final map. The mean value for $\mathrm{Cu}$ is (66.7 P.P.M.), $\mathrm{Pb}$ is (160.4 P.P.M.) and $\mathrm{Zn}$ is (92 P.P.M.). As the last step the drainage geochemical final (Figure 11) map was integrated with the final alteration map in GIS area (Figure 12).

\section{Conclusion}

The result of integration between alteration and geo-chemical data indicates that the situation of locating the altration zones are in a NW - SE striking band in the middle of the sheet. There is probably a porphyry system, cause of locating the propylitic alteration zone around the argillic alteration zone, especially in south east of this band. The overlapping between argillic alteration and iron oxide zones are indicating the presence of sulfide deposits. 

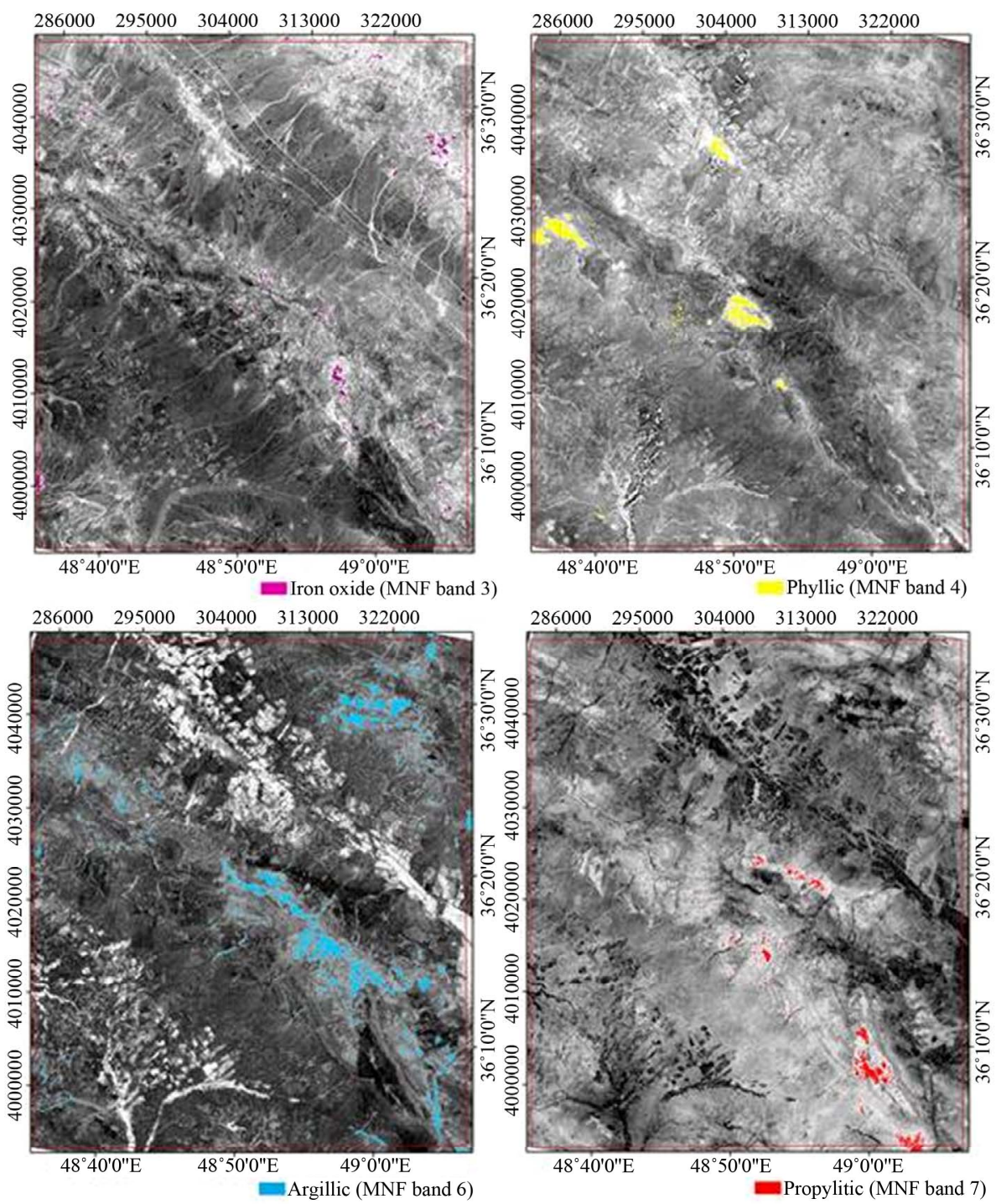

$\mathrm{w} \rightarrow \mathrm{S}_{\mathrm{S}}^{\mathrm{N}} \mathrm{420}$ 4Kilometers

Figure 6. The iron oxide, argillic, phyllic and propylitic images prepared based on MNF method.
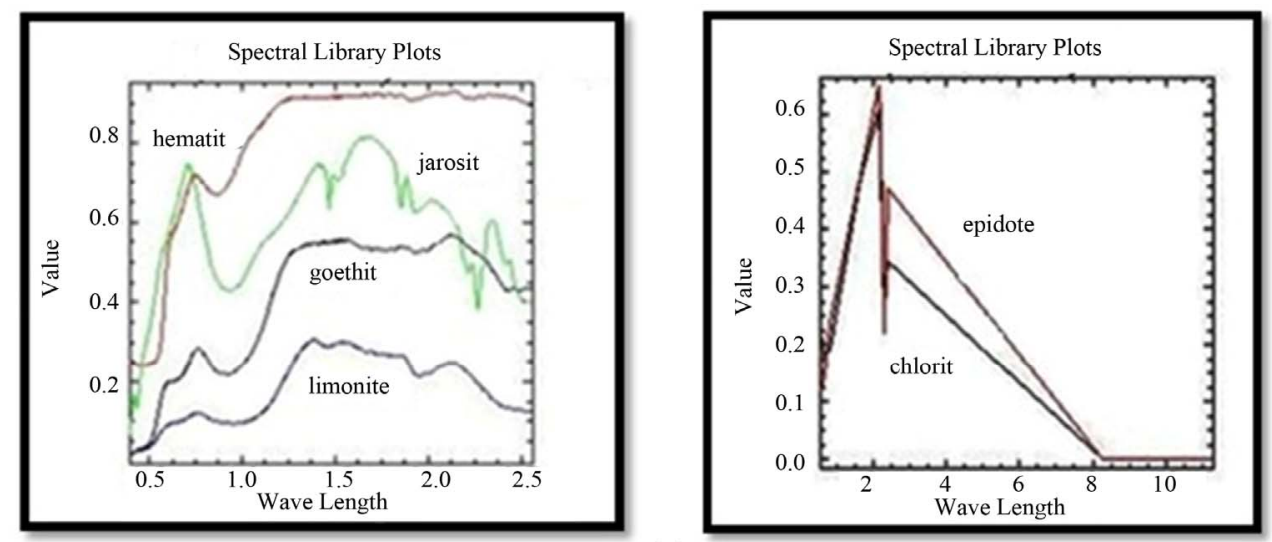

Figure 7. Spectral library plots from USGS library. 


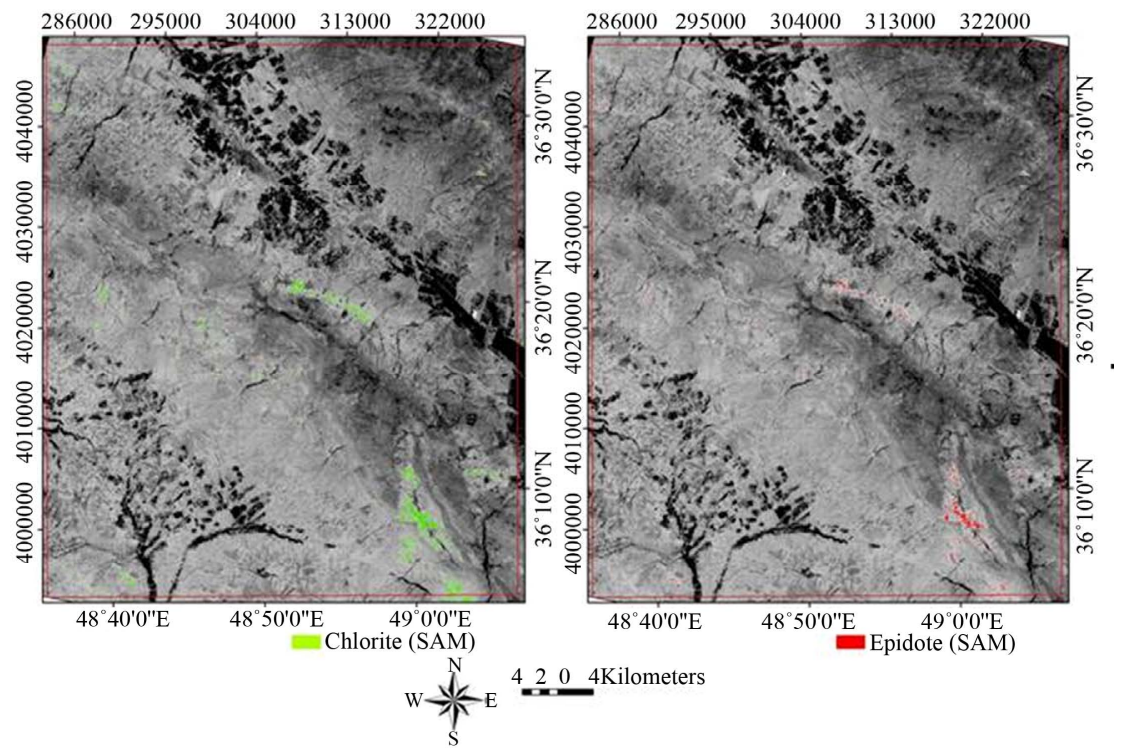

Figure 8. The propylitic images prepared based on SAM method.
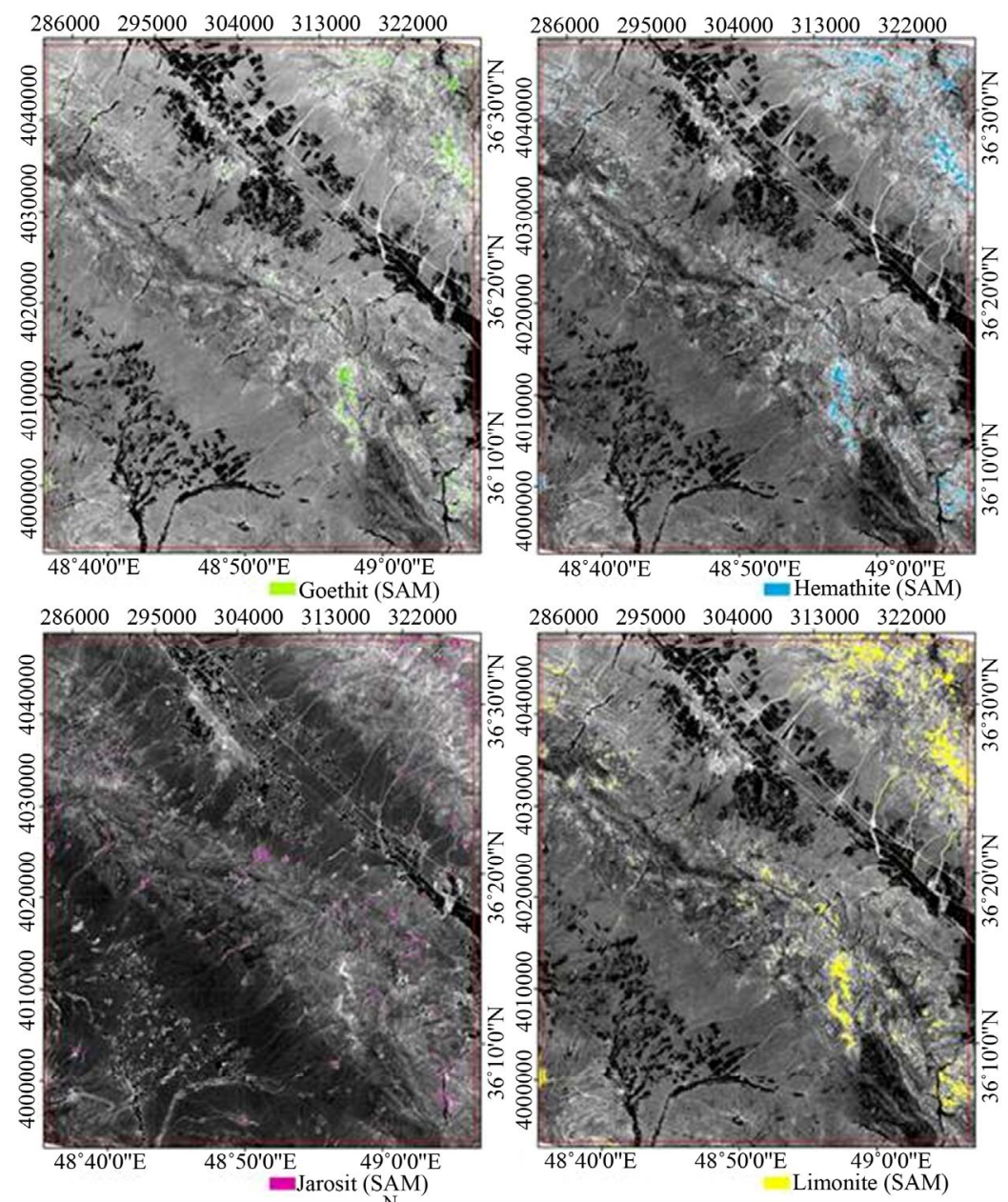

$\mathrm{W}$ 年

Figure 9. The Iron oxide images prepared based on SAM method. 


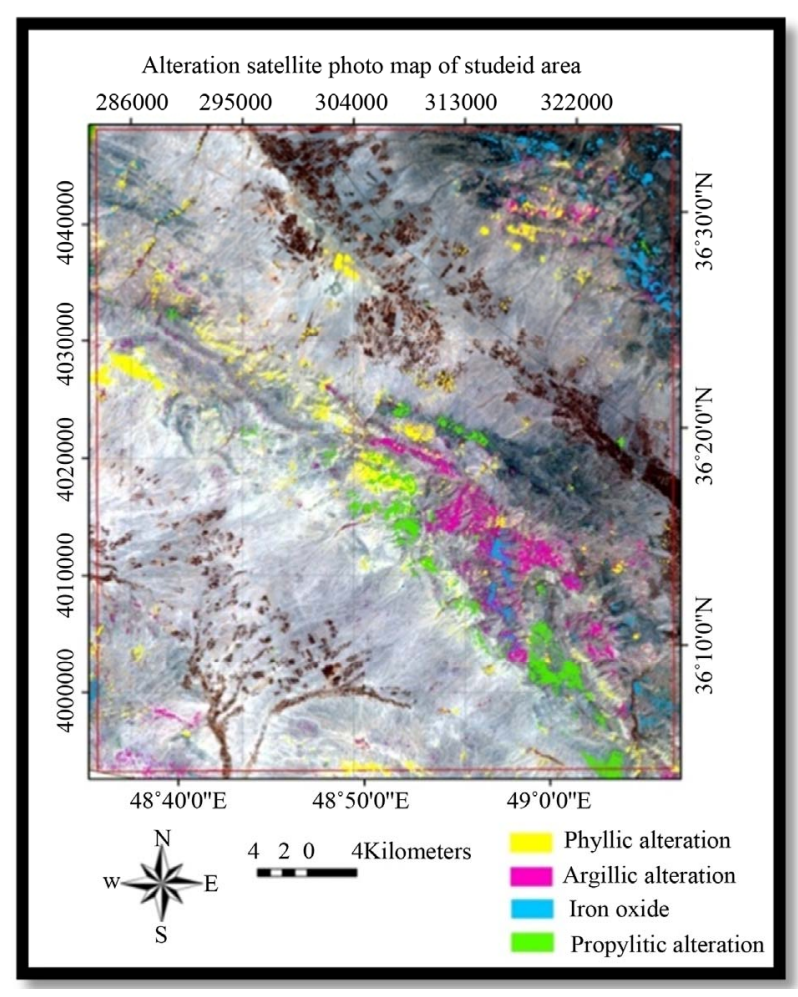

Figure 10. Final alteration map of studied area.

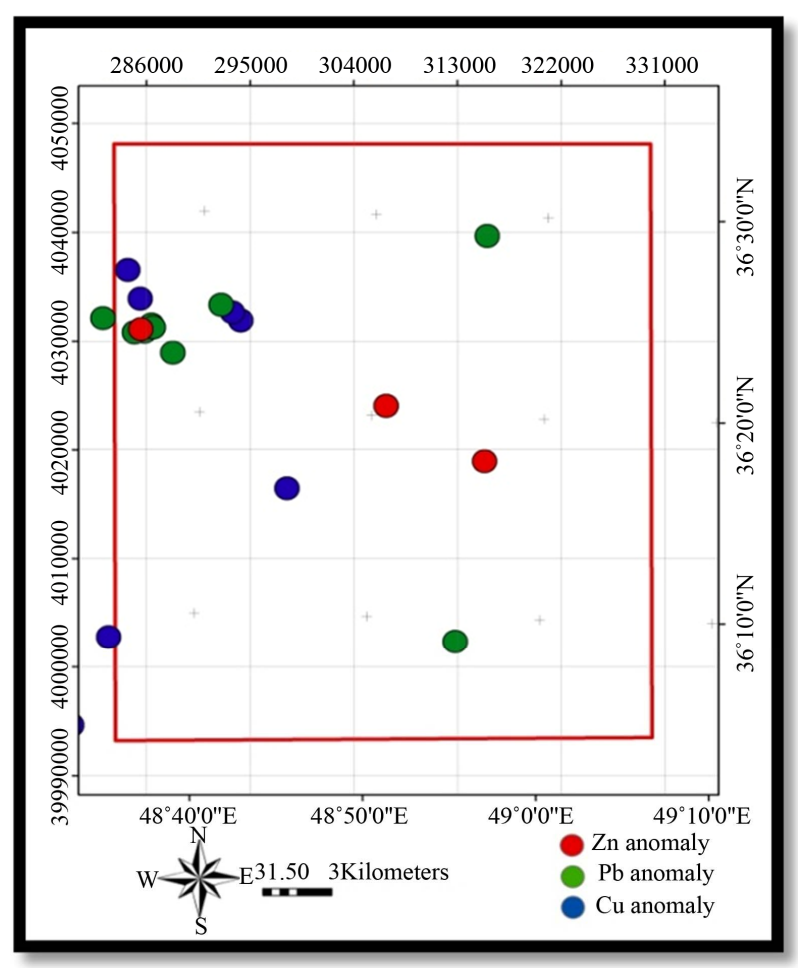

Figure 11. Final geochemical map of studied area.

The phyllic alteration zone is existing in the middle of the band, especially in northwest of the location, where the intrusive bodies are. Also there is a good overlapping

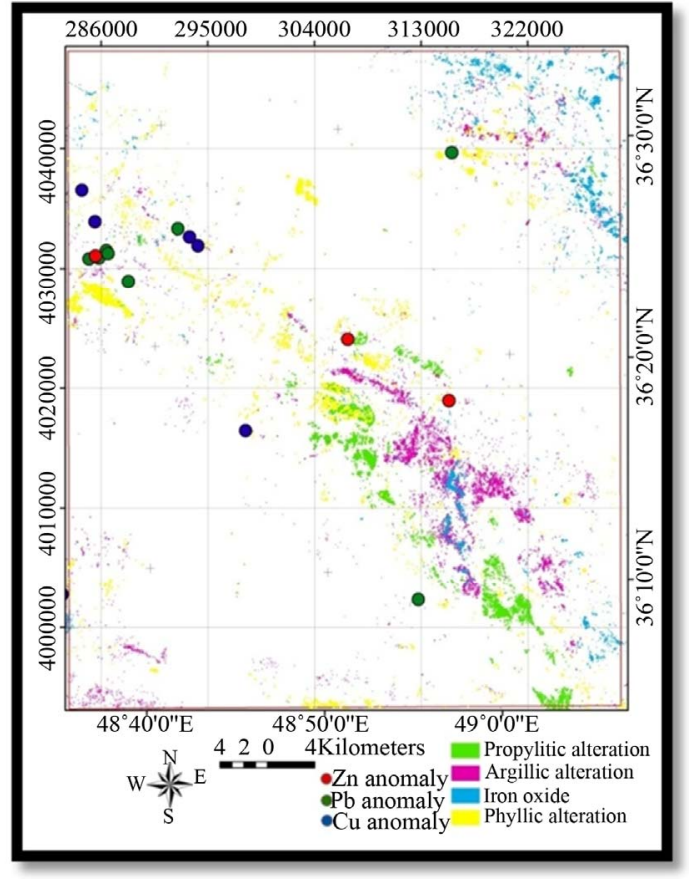

Figure 12. Integration of alteration and drainage geo-chemical data.

between geochemical anomalies and phyllic alteration zone which requests more research.

\section{REFERENCES}

[1] S. M. Salem and S. A. A. Ramadan, "Exploration of Copper Deposits in Wadi El Regeita Area, Southern Sinai, Egypt, with Contribution of Remote Sensing and Geophysical Data," Arabian Journal Geoscience, Vol. 6, No. 2, 2011, pp. 321-335. doi:10.1007/s12517-011-0346-Z

[2] A. Javed and M. H. Wani, "Delineation of Groundwater Potential Zones in Kahund Watershed, Eastern Rajasthan, Using Remote Sensing and GIS Techniques," Journal Geological Society of India, No. 73, 2009, pp. 229-236.

[3] C. P. Kujjo, "Application of Remote Sensing for Gold Exploration in the Nuba Montains, Sudan," Master of Science Thesis, Bowling Green State University, Bowling Green, 2010.

[4] H. A. Haroni and A. Lavafan, "Integrated Analysis of ASTER and Landsat ETM Data to Map Exploration Targets in the Muteh Gold-Mining Area, IRAN," 5th International Symposium on Spatial Data Quality, Enschede, 2007.

[5] H. Azizi, M. A. Tarverdi and A. Akbarpour, "Extraction of Hydrothermal Alterations from ASTER SWIR Data from East Zanjan, Northern Iran," Advances in Space Research, Vol. 46, No. 1, 2010, pp. 99-109. doi:10.1016/j.asr.2010.03.014

[6] R, Noori, "The Studies of Relationship between Metalic Mineralization and Tectonic in North of Zanjan-Saiinghaleh," 2013.

[7] F. Feizi and M. Arian, "The Role of Structural Control- 
lers in Geneses of Copper Deposits in 1:50,000 Map of Saiinghaleh," Journal of Sciences, Islamic Azad University, Vol. 21, No. 81, 2011.

[8] H. A. Gilg, M. Boni, G. Balassone, R. Cameron, Allen, R. C. D. Banks and F. Moore, "Marble-Hosted Sulfide Ores in the Angouran $\mathrm{Zn}-(\mathrm{Pb}-\mathrm{Ag})$ Deposit, NW Iran: Interaction of Sedimentary Brines with a Metamorphic Core Complex," Mineral Deposita, Vol. 41, 2005, pp. 1-16.

[9] M. Boni, H. A. Gilg, G. Balassone, J. Schneider, C. R. Allen and F. Moore, "Hypogene Zn Carbonate Ores in the Angouran Deposit, NW Iran,” Mineral Deposita, Vol. 42, 2007, pp. 799-820. doi:10.1007/s00126-007-0144-4

[10] H. Watanabe and K. Matsuo, "Rock Type Classification by Multi-Band TIR of ASTER," Geoscience Journal, Vol. 7, No. 4, 2003, pp. 347-358.

[11] J. Inzana, T. Kusky, G. Higgs and R. Tucker, "Supervised Classifications of Landsat TM Band Ratio Images and Landsat TM Band Ratio Image with Radar for Geological Interpretations of Central Madagascar," Journal of African Earth Sciences, Vol. 37, 2003, pp. 59-72.

[12] X. Zhanga, M. Paznera and N. Duke, "Lithologic and Mineral Information Extraction for Gold Exploration Using ASTER Data in the South Chocolate Mountains (California)," ISPRS Journal of Photogrammetry and Remote Sensing, Vol. 62, 2007, pp. 271-282.

[13] E. Yetkin, V. Toprak and M. L. Suezen, “Alteration Mapping by Remote Sensing: Application to Hasandağ-Melendiz Volcanic, Complex," Geo-Imagery Bridging Continents 10th ISPRS Congress, Istanbul, 2004.

[14] A. B. Pour and M. Hashim, "Identifying Areas of High Economic-Potential Copper Mineralization Using ASTER Data in the Urumieh-Dokhtar Volcanic Belt, Iran," Ad- vances in Space Research, Vol. 49, 2012, pp. 753-769.

[15] G. Sarp, "Lineament Analysis from Satellite Images, NorthWest of Ankara, Master of Science Dissertation," School of Natural and Applied Science of Middle East Technical University, 2005.

[16] S. E. Papadaki, S. P. Mertikas and A. Sarris, "Identification of Lineaments with Possible Structural Origin Using ASTER Images and DEM Derive Products in Western Crete, GREECE," European Association of Remote Sensing Laboratories (ARSeL), 2011.

[17] A. F. Weldemariam, "Mapping Hydrothermally Altered Rocks and Lineament Analysis through Digital Enhancement of ASTER Data Case Study: Kemashi Area, Western Ethiopia," Master of Science Dissertation, Addis Ababa University, Addis Ababa, 2009.

[18] A. B. Pour, M. Hashim and M. Marghany, "Using Spectral Mapping Techniques on Short Wave Infrared Bands of ASTER Remote Sensing Data for Alteration Mineral Mapping in SE Iran," International Journal of the Physical Sciences, Vol. 6, No. 4, 2011, pp. 917-929.

[19] F. A. Kruse, J. W. Boardman, A. B. Lefkoff, K. B. Heidebrecht, A. T. Shapiro, P. J. Barloon and A. F. H. Goetz, "The Spectral Image Processing System (SIPS) - Interactive Visualization and Analysis of Imaging Spectrometer Data," Remote Sensing of Environment, Vol. 44, 1993, pp. 145-163.

[20] A. Malekzadeh, M. H. Karimpour, C. R. Stern and S. A. Mazaheri, "Hydrothermal Alteration Mapping in SW Birjand, Iran, Using the Advanced Spaceborne Thermal Emission and Reflection Radiometer (ASTER) Image Processing," Journal of Applied Sciences, Vol. 9, No. 5, 2009, pp. 829-842. 